\title{
Oxygen dependence of endothelium-dependent vasodilation: importance in chronic obstructive pulmonary disease
}

\author{
Stefanie Keymel ${ }^{1}$, Benedikt Schueller ${ }^{1}$, Roberto Sansone ${ }^{1}$, Rabea Wagstaff ${ }^{1}$, Stephan Steiner ${ }^{2}$, \\ Malte Kelm ${ }^{1}$, Christian Heiss ${ }^{1}$
}

\begin{abstract}
${ }^{1}$ Division of Cardiology, Pulmonology and Vascular Medicine, Medical Faculty, University Duesseldorf, Duesseldorf, Germany

${ }^{2}$ Department of Medicine, Division of Cardiology, Pneumology and Intensive Care Medicine, St. Vincenz Hospital, Limburg/Lahn, Germany
\end{abstract}

Submitted: 12 December 2015

Accepted: 27 January 2016

Arch Med Sci 2018; 14, 2: 297-306

DOI: 10.5114/aoms.2016.58854

Copyright $\odot 2016$ Termedia \& Banach

\section{Abstract}

Introduction: Epidemiological studies have shown increased morbidity and mortality in patients with coronary artery disease (CAD) and chronic obstructive pulmonary disease (COPD). We aimed to characterize the oxygen dependence of endothelial function in patients with CAD and coexisting COPD. Material and methods: In CAD patients with and without COPD $(n=33)$, we non-invasively measured flow-mediated dilation (FMD) and intima-media thickness (IMT) of the brachial artery (BA), forearm blood flow (FBF), and perfusion of the cutaneous microcirculation with laser Doppler perfusion imaging (LDPI). In an experimental setup, vascular function was assessed in healthy volunteers $(n=5)$ breathing $12 \%$ oxygen or $100 \%$ oxygen in comparison to room air.

Results: COPD was associated with impaired FMD ( $3.4 \pm 0.5$ vs. $4.2 \pm 0.6 \%$; $p<0.001)$ and increased IMT $(0.49 \pm 0.04$ vs. $0.44 \pm 0.04 \mathrm{~mm} ; p<0.01)$, indicating functional and structural alterations of the BA in COPD. Forearm blood flow and LDPI were comparable between the groups. Flow-mediated dilation correlated with capillary oxygen pressure $\left(\mathrm{pO}_{2}, r=0.608\right)$. Subgroup analysis in COPD patients with $\mathrm{pO}_{2}>65 \mathrm{~mm} \mathrm{Hg}$ and $\mathrm{pO}_{2} \leq 65 \mathrm{~mm} \mathrm{Hg}$ revealed even lower FMD in patients with lower $\mathrm{pO}_{2}$ (3.0 \pm 0.5 vs. $3.7 \pm 0.4 \%$; $p<0.01$ ). Multivariate analysis showed that $\mathrm{pO}_{2}$ was a predictor of FMD independent of the forced expiratory volume and pack years. Exposure to hypoxic air led to an acute decrease in FMD, whereby exposure to $100 \%$ oxygen did not change vascular function.

Conclusions: Our data suggest that in CAD patients with COPD, decreased systemic oxygen levels lead to endothelial dysfunction, underlining the relevance of cardiopulmonary interaction and the potential importance of pulmonary treatment in secondary prevention of vascular disease.

Key words: chronic obstructive pulmonary disease, coronary artery disease, endothelial function, flow-mediated dilation, intima media thickness, oxygen.

\section{Introduction}

Chronic obstructive pulmonary disease (COPD) and cardiovascular disease are relevant comorbidities with increased cardiovascular mor-

\author{
Corresponding author: \\ Christian Heiss MD, PhD \\ Division of Cardiology, \\ Pulmonology and \\ Vascular Medicine \\ Medical Faculty \\ University Duesseldorf \\ Moorenstr. 5 \\ 40225 Duesseldorf, Germany \\ Phone: +498108753 \\ E-mail: christian.heiss@med. \\ uni-duesseldorf.de
}


bidity and mortality in patients with COPD [1-3]. Concerning coronary artery disease (CAD), previous studies have shown increased mortality after myocardial infarction [4], after coronary artery bypass grafting [5] or percutaneous coronary interventions [6] in patients with coexisting COPD.

Epidemiological studies have related increased cardiovascular risk with the forced expiratory volume in $1 \mathrm{~s}\left(\mathrm{FEV}_{1}\right)$ as a measure of lung function impairment and disease severity [2, 7]. The underlying mechanisms are currently under investigation. Undoubtedly, smoking as the relevant shared risk factor for cardiovascular disease and for COPD explains coexistence of both diseases. However, there is increasing evidence that cardiovascular disease may be considered as a systemic feature of COPD [8]. As potential links, systemic inflammation, oxidative stress, hypoxia, accelerated aging, impaired endothelial regeneration, protease/antiprotease imbalance as well as systemic vascular dysfunction are currently under investigation [8-12]. Previously, correlations of FEV with impaired flow-mediated dilation as a marker of endothelial dysfunction [13-15], increased arterial stiffness $[16,17]$ or increased intima-media thickness of the carotid artery as a marker for structural alterations [18-20] have been found in patients with stable COPD.

The above described systemic vascular alterations have been found in patients with COPD in comparison to control subjects who typically are smokers without COPD. However, due to relevant prevalence of comorbidity of COPD and CAD, consequences of COPD in patients with prevalent atherosclerotic disease are of high interest. Until now, it is unknown whether COPD aggravates endothelial

A

Role of oxygen for vascular function in COPD

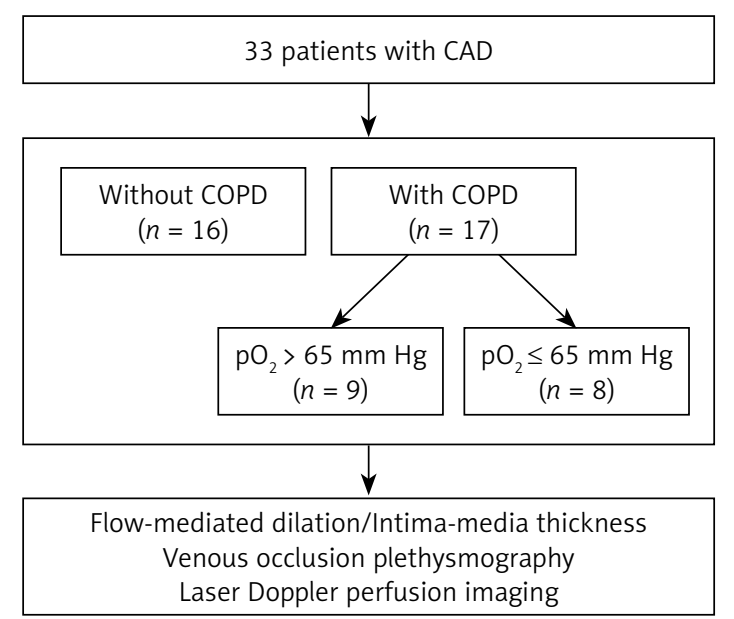

dysfunction in the presence of cardiovascular disease, potentially contributing to adverse outcomes from atherosclerotic disease and coexisting COPD.

Therefore, the aim of the current study was to non-invasively characterize vascular function and structure in CAD patients with or without COPD. Furthermore, we analyzed the relation of vascular properties with systemic oxygen as a potential mediator of endothelial dysfunction in COPD patients and experimental hypoxemia in healthy control subjects.

\section{Material and methods}

\section{Study populations}

Protocol 1: We studied 33 male patients with CAD with or without coexisting COPD (CAD + COPD: $n=17$, CAD: $n=16$; Figure 1 A). All subjects were screened by clinical history, physical examination, lung function test (Jaeger Master Screening Body, Care Fusion, Hoechberg, Germany), including capillary blood gases (ABL 800 Flex, Radiometer, Willich, Germany), and routine chemical analysis. The glomerular filtration rate was calculated by the Modification of Diet in Renal Disease (MDRD) study equation. Chronic obstructive pulmonary disease was defined by clinical symptoms such as dyspnea or chronic cough, smoking history and the presence of a $\mathrm{FEV}_{1} / \mathrm{VC}$ ratio $<0.7$ by spirometry [21] or current antiobstructive medication. Coronary artery disease was diagnosed by coronary angiography. Patients with severe chronic heart failure, advanced chronic renal failure, an active malignant disease, an inflammatory disease, vasculitis, Raynaud's syndrome or with an acute exacerbation of the COPD were excluded.

\section{B}

Role of oxygen for vascular function in healthy subjects

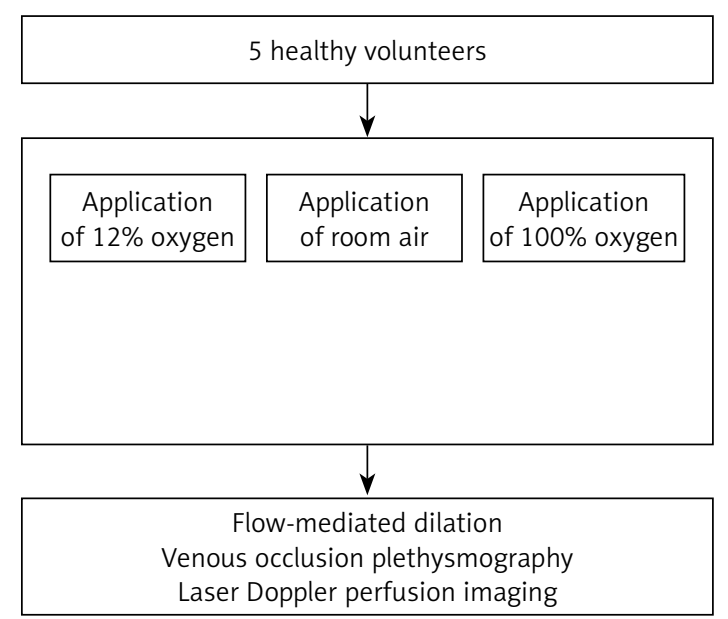

Figure 1. Study flow diagram. We studied vascular function in 33 patients with coronary artery disease (CAD) with or without coexisting chronic obstructive pulmonary disease (COPD). Subgroup analysis was performed comparing COPD patients with capillary $\mathrm{pO}_{2}>65 \mathrm{~mm} \mathrm{Hg}$ or reduced capillary $\mathrm{pO}_{2} \leq 65 \mathrm{~mm} \mathrm{Hg}(\mathbf{A})$. Also, vascular function in healthy volunteers exposed to different fractions of inspired oxygen was investigated $(n=5 ; \mathbf{B})$ 
Protocol 2: For the interventional study applying different fractions of inspired oxygen we studied 5 young healthy male volunteers ( $24 \pm 1$ years; Figure $1 \mathrm{~B})$. Healthy subjects were screened by clinical history and physical examination. Healthy volunteers were not taking any regular medication.

The study was registered for clinical trials at ClinicalTrials.gov with the registration number NCT02127333. The study was approved by the local ethics committee and written informed consent was obtained from all study subjects prior to enrolment.

\section{Study protocols}

All investigations were performed in the morning between 8:00 and 11:00 a.m. in an air-conditioned room at $23 \pm 2^{\circ} \mathrm{C}$. Cigarettes, beverages containing caffeine, and alcohol were prohibited for at least $12 \mathrm{~h}$ prior to the investigation. Each subject rested in a supine position quietly for at least $10 \mathrm{~min}$ before the first scan.

Protocol 1: In the patient group, vascular studies were performed on a single day. Vascular ultrasound studies of the brachial artery including flow-mediated dilation, intima-media thickness, and endothelium-independent dilatation were measured on the right arm. Venous occlusion plethysmography and laser Doppler perfusion imaging were measured on the left arm.

Protocol 2: For testing the effect of variations in systemic oxygen levels in healthy volunteers, vascular studies were performed on the three separate days under the same conditions. Vascular studies were performed while breathing room air $\left(\mathrm{FiO}_{2} 21 \%\right)$, by breathing oxygen rich air (10 l/ min oxygen $100 \%$ (Linde, Munich, Germany)) or oxygen poor air (10 l/min oxygen $12 \%$ (Linde)) via a full face mask for noninvasive ventilation (Fischer \& Paykel, East Tamaki, New Zealand) connected with a reservoir bag. To reach a steady state, measurements were started 30 min after induction of the certain condition. Heart rate, blood pressure and oxygen saturation were recorded for safety reasons. Capillary blood gases from the hyperemic ear lobe were taken once during each condition. Vascular ultrasound studies of the brachial artery were measured on the right arm. Venous occlusion plethysmography and laser Doppler perfusion imaging were performed on the left arm.

\section{Flow-mediated dilation}

Flow-mediated brachial artery dilation was measured as previously described [22]. Briefly, the diameter of the brachial artery was measured from images assessed with a $15 \mathrm{MHz}$ linear array transducer (Vivid i, GE Healthcare) using an automated software analysis (Brachial Analyzer,
Medical Imaging Applications, Iowa City, IA, USA). Following measurement of the baseline diameter of the brachial artery (BA), a blood pressure tourniquet located at the proximal forearm was inflated to a pressure of $200 \mathrm{~mm} \mathrm{Hg}$ for $5 \mathrm{~min}$. Brachial artery dilation following reactive hyperemia was recorded for 60-90 s after release of the cuff. Endothelium-independent dilation of the brachial artery was measured after sublingual nitroglycerin (NTG $400 \mu \mathrm{g}$ ). The time interval between the end of hyperemia and the NTG test was $20 \mathrm{~min}$ to re-establish baseline conditions. Both flow-mediated dilation (FMD) and endothelium-independent vasodilation following nitroglycerin were expressed as the percent increase compared to the diameter of the resting scans.

\section{Intima-media thickness}

Images for the measurement of the brachial artery IMT were assessed during the same setting with the FMD as previously described [23]. In order to evaluate IMT, a scan was made in a longitudinal section with regards to a clear differentiation of the intima-media complex of the posterior wall. PC-based measurement of IMT was performed according to the method of Wendelhag et al. [24] using an automated analysis system (Artery Measurement System, AMS, Wallenberg Laboratory for Cardiovascular Research, Goteborg, Sweden).

\section{Venous occlusion plethysmography}

Forearm blood flow (FBF) was measured by mercury-in-rubber strain gauge plethysmography (Periquant 833, Gutman, Eurasburg, Germany) according to standard techniques as previously described [25]. The FBF was measured at rest and during reactive hyperemia and expressed as $\mathrm{ml}$ $\min \times 100 \mathrm{ml}$ of tissue.

\section{Laser Doppler perfusion imaging}

Cutaneous microcirculation was measured by laser Doppler perfusion imaging (LDPI, PeriScan PIM III, Perimed, Sweden) as previously described [26]. Briefly, measurement was performed on the volar site of the forearm that was immobilized by a vacuum pillow (Germa, Sweden). A field of $200 \mathrm{~cm}^{2}$ was scanned consisting of 64 measurement sites. Baseline measurement was performed for 1 min (20 measurements). Microvascular reactivity was assessed during postocclusive reactive hyperemia (PORH), which was induced by suprasystolic inflation of a blood pressure cuff for $5 \mathrm{~min}$. After the cuff release, the microvascular response to reactive hyperemia was recorded for $5 \mathrm{~min}$. Data acquisition and analysis were performed by LDPIWin software (Perimed, Sweden). Baseline 
perfusion was calculated as the mean of 20 measurements. Maximum perfusion was the peak value of perfusion after cuff release.

\section{Statistical analysis}

Data are expressed as means \pm SEM. Comparisons between groups were analyzed for normal distribution using the Shapiro-Wilk test. The $\chi^{2}$ test was used for comparison of non-continuous data. For comparing differences between patient groups the unpaired Student $t$-test was used, while for comparing differences between the interventions in healthy volunteers the paired Student $t$-test was used. Univariate correlations were calculated using Pearson's coefficient $(r)$. $P$-values $\leq 0.05$ were accepted as statistically significant. To estimate the independence of $\mathrm{pO}_{2}$ in predicting vascular function measured by FMD, a multivariate linear regression analysis was performed. With respect to the number of study subjects, $\mathrm{pO}_{2}, \mathrm{FEV}_{1}$ and pack years of smoking were included in the analysis. Data processing was performed with the software modules of IBM SPSS
(Statistical package for the social sciences, software release 22, SPSS Inc., Chicago, USA).

\section{Results}

\section{Patient characteristics}

We studied 33 male patients with CAD with or without coexisting COPD (CAD + COPD: $n=17$, age: $66 \pm 8$ years; CAD: $n=16$, age $64 \pm 10$ years). The clinical characteristics of the patient groups are presented in Table I. All patients were male. The study groups were well matched for cardiovascular risk factors such as age, blood pressure, and lipid and glucose levels. Study subjects with COPD included patients with COPD GOLD stages I-IV and with previously known (treated or untreated) or previously not diagnosed COPD. All patients were former smokers, which excludes effects of acute smoking or deprivation of smoking for study of vascular function. However, as expected, patients with COPD had a significantly higher number of pack years ( $50 \pm 20$ vs. $30 \pm 17, p=0.005)$ and significantly reduced $\mathrm{FEV}_{1}(1.9 \pm 0.7$ vs. $3.0 \pm 0.5 \mathrm{l}, p \leq 0.001)$

Table I. Clinical characteristics

\begin{tabular}{|c|c|c|c|c|}
\hline Parameter & Unit & CAD without COPD & CAD with COPD & $P$-value \\
\hline Number & & 16 & 17 & \\
\hline Age & [years] & $64 \pm 10$ & $66 \pm 8$ & 0.520 \\
\hline Body mass index & {$\left[\mathrm{kg} / \mathrm{m}^{2}\right]$} & $28 \pm 4$ & $29 \pm 3$ & 0.275 \\
\hline CAD (1-/2-/3-vessel disease) & {$[n]$} & $2 / 1 / 13$ & $4 / 2 / 11$ & 0.566 \\
\hline Current/former smoker & {$[n]$} & $0 / 16$ & $0 / 17$ & \\
\hline Pack years & & $30 \pm 17$ & $50 \pm 20$ & 0.005 \\
\hline $\mathrm{FEV}_{1}$ & {$[1]$} & $3.0 \pm 0.5$ & $1.9 \pm 0.7$ & $<0.001$ \\
\hline $\mathrm{FEV}_{1} \%$ pred. & {$[\%]$} & $95 \pm 17$ & $59 \pm 17$ & $<0.001$ \\
\hline $\mathrm{FEV}_{1} / \mathrm{VC}$ & {$[\%]$} & $76 \pm 5$ & $61 \pm 14$ & 0.001 \\
\hline Capillary $\mathrm{O}_{2}$ pressure & {$[\mathrm{mm} \mathrm{Hg}]$} & $77 \pm 8$ & $66 \pm 11$ & 0.002 \\
\hline Capillary $\mathrm{CO}_{2}$ pressure & {$[\mathrm{mm} \mathrm{Hg}]$} & $36 \pm 3$ & $38 \pm 5$ & 0.431 \\
\hline $\mathrm{pH}$ & & $7.44 \pm 0.04$ & $7.42 \pm 0.04$ & 0.105 \\
\hline $\mathrm{HCO}_{3}$ & {$[\mathrm{mmol} / \mathrm{l}]$} & $25 \pm 2$ & $24 \pm 3$ & 0.574 \\
\hline Heart rate & {$[\mathrm{bpm}]$} & $66 \pm 13$ & $69 \pm 10$ & 0.542 \\
\hline Systolic blood pressure & {$[\mathrm{mm} \mathrm{Hg}]$} & $139 \pm 13$ & $138 \pm 14$ & 0.719 \\
\hline Diastolic blood pressure & {$[\mathrm{mm} \mathrm{Hg}]$} & $84 \pm 10$ & $83 \pm 8$ & 0.720 \\
\hline Total cholesterol & {$[\mathrm{mg} / \mathrm{dl}]$} & $173 \pm 27$ & $191 \pm 27$ & 0.100 \\
\hline Triglycerides & {$[\mathrm{mg} / \mathrm{dl}]$} & $184 \pm 168$ & $168 \pm 55$ & 0.761 \\
\hline Plasma glucose & {$[\mathrm{mg} / \mathrm{dl}]$} & $123 \pm 37$ & $117 \pm 34$ & 0.639 \\
\hline Glomerular filtration rate & {$[\mathrm{mg} / \mathrm{dl}]$} & $85 \pm 20$ & $75 \pm 18$ & 0.145 \\
\hline C-reactive protein & {$[\mathrm{mg} / \mathrm{dl}]$} & $0.4 \pm 0.1$ & $0.5 \pm 0.5$ & 0.279 \\
\hline White blood cell count & {$[G / I]$} & $6.7 \pm 1.6$ & $8.1 \pm 3.2$ & 0.124 \\
\hline Red blood cell count & {$[\mathrm{T} / \mathrm{I}]$} & $4.8 \pm 0.4$ & $4.6 \pm 0.4$ & 0.099 \\
\hline Hemoglobin concentration & [g/l] & $15 \pm 1.0$ & $14 \pm 1.4$ & 0.136 \\
\hline Hematocrit & [\%] & $44 \pm 2.7$ & $42 \pm 3.9$ & 0.235 \\
\hline
\end{tabular}

$C A D$ - coronary artery disease, $F E V_{1}$ - forced expiratory volume in $1 \mathrm{~s}, V C$ - vital capacity. 
and $\mathrm{FEV}_{1} \%$ predicted ( $\mathrm{FEV}_{1} \%$ pred $59 \pm 17$ vs. 95 $\pm 17 \%, p \leq 0.001$ ). Capillary blood gases showed a significantly reduced $\mathrm{pO}_{2}$ in COPD patients ( $66 \pm 11$ vs. $77 \pm 8 \mathrm{~mm} \mathrm{Hg}, p=0.002$ ), while $\mathrm{pCO}_{2}$ was comparable between the study groups (38 \pm 5 vs. $36 \pm 3 \mathrm{~mm} \mathrm{Hg}, p=0.431)$. The medication for cardiovascular diseases (aspirin, clopidogrel, statin, $\beta$-blocker, ACE inhibitor or angiotensin receptor antagonist, diuretics, calcium channel blocker, oral antidiabetics, insulin) was comparable between the study groups. In the COPD study group, antiobstructive and anti-inflammatory medication included $\beta 2$-agonists (71\% vs. $0 \% ; p<0.001$ ), anticholinergics ( $47 \%$ vs. $0 \% ; p=0.002$ ), inhaled glucocorticosteroids ( $47 \%$ vs. $0 \% ; p=0.002$ ), and oral glucocorticosteroids ( $6 \%$ vs. $0 \%, p=0.325$ ).

\section{Endothelial function}

Flow-mediated dilation of the BA was significantly lower (3.4 \pm 0.5 vs. $4.2 \pm 0.6 \%, p \leq 0.001$; Figure $2 \mathrm{~A}$ ) in patients with COPD as compared to control subjects, while baseline BA diameters were not different $(4.65 \pm 0.60 \mathrm{~mm}$ vs. $4.59 \pm 0.65 \mathrm{~mm}$, $p=0.784)$. Endothelium-independent dilation of the BA was comparable between the study groups $(7.8 \pm 2.5$ vs. $8.9 \pm 2.5 \%, p=0.461)$.

\section{Vascular structure}

Intima-media thickness of the BA was significantly greater $(0.49 \pm 0.04$ vs. $0.44 \pm 0.04 \mathrm{~mm}, p=0.003$; Figure $2 \mathrm{~B}$ ) in patients with COPD as compared to control patients. Increased IMT reflects accelerated structural alterations in patients with COPD.

\section{Microvascular function of resistance arteries}

Microvascular function of the resistance arteries was comparable between the study groups' forearm blood flow at rest and after reactive hyperemia (FBF at rest: $1.5 \pm 1.0$ vs. $1.2 \pm 0.9 \mathrm{ml} / \mathrm{min}$ $\times 100 \mathrm{ml}$ tissue, $p=0.498$, FBF during reactive hyperemia: $9.8 \pm 4.6$ vs. $8.9 \pm 3.8 \mathrm{ml} / \mathrm{min} \times 100 \mathrm{ml}$ tissue, $p=0.577$; Figure $2 \mathrm{C}$ ).

\section{Microvascular function of capillaries}

Microvascular function of the cutaneous capillaries also was not different between the study groups. Neither baseline perfusion nor maximum perfusion during reactive hyperemia was different between the study groups (baseline perfusion: 42 \pm 17 vs. $36 \pm 12 \mathrm{PU}, p=0.291$; maximum perfusion: $127 \pm 37$ vs. $120 \pm 31 \mathrm{PU}, p=0.549$ ).

\section{Correlation of flow-mediated dilation and pulmonary function}

Flow-mediated dilation showed significant correlations with vital capacity (VC; $r=0.521$, $p=0.002), \operatorname{FEV}_{1}(r=0.588 ; p \leq 0.001), \mathrm{FEV}_{1} \%$ pred $(r=0.620, p \leq 0.001$; Figure $2 \mathrm{D})$, and $\mathrm{FEV}_{1} / \mathrm{VC}$ $(r=0.403, p=0.022)$, indicating a relation between vascular function, lung volume, and pulmonary obstruction. Further correlations between vascular characteristics and $\mathrm{FEV}_{1}$ are presented in Table II.

\section{Correlation of flow-mediated dilation and blood gases}

Blood oxygen levels were associated with FMD, as indicated by significant correlations between FMD and $\mathrm{pO}_{2}(r=0.608, p \leq 0.001$; Figure $2 \mathrm{E}), \mathrm{SO}_{2}(r=$ $0.641, p \leq 0.001)$ or oxygen content $(r=0.621, p \leq$ 0.001 ). When considering COPD patients only, even a stronger linear correlation of FMD and $\mathrm{pO}_{2}$ was found $(r=0.748, p \leq 0.001)$, while in patients with $C A D$ without $C A D$ (in patients with $C A D$ without COPD) no correlation was found $(r=0.021, p=0.939)$.

Also, FMD showed an inverse correlation with $\mathrm{pCO}_{2}(r=0.493, p=0.004)$. Further correlations between vascular characteristics and $\mathrm{pO}_{2}$ are presented in Table II.

A multivariate linear regression analysis including $\mathrm{pO}_{2}, \mathrm{FEV}_{1}$ and pack years of smoking showed that $\mathrm{pO}_{2}$ (standardized coefficient $\beta=0.024$; $p=0.043)$ was a significant predictor of FMD ( $p($ ANOVA $) \leq 0.001$; adjusted $\left.R^{2}=0.405\right)$ independent of $\operatorname{FEV}_{1}(\beta=0.274 ; p=0.077)$ and pack years $(\beta=-0.003 ; p=0.551)$.

\section{Subgroup analysis in COPD patients}

Subgroup analysis was performed in the study group of COPD patients to estimate the role of hypoxemia for vascular function. For this purpose, COPD patients were divided into a subgroup of patients with reduced oxygen levels of $\mathrm{pO}_{2}$ $\leq 65 \mathrm{~mm} \mathrm{Hg}\left(\mathrm{COPD} \leq 65 ; n=8 ; \mathrm{pO}_{2} 57 \pm 8 \mathrm{~mm} \mathrm{Hg}\right)$ and a subgroup of patients with $\mathrm{pO}_{2}>65 \mathrm{~mm} \mathrm{Hg}$ (COPD > 65; $n=9 ; \mathrm{pO}_{2} 74 \pm 8 \mathrm{~mm} \mathrm{Hg}$ ).

\section{Macrovascular function and structure}

In COPD patients with $\mathrm{pO}_{2} \leq 65 \mathrm{~mm} \mathrm{Hg}$, FMD was significantly lowered in comparison to COPD patients with $\mathrm{pO}_{2}>65 \mathrm{~mm} \mathrm{Hg}(3.0 \pm 0.5$ vs. 3.7 $\pm 0.4 \%, p=0.008$; Figure $3 \mathrm{~A}$ ). Baseline diameter of the brachial artery was slightly increased in COPD patients with reduced oxygen levels. However, the difference did not reach statistical significance (4.8 \pm 0.7 vs. $4.5 \pm 0.5 \mathrm{~mm}, p=0.293$ ). Intima-media thickness of the brachial artery was comparable between the subgroups of COPD patients ( 0.49 \pm 0.05 vs. $0.48 \pm 0.04 \mathrm{~mm} ; p=0.519$; Figure $3 \mathrm{~B}$ ).

\section{Microvascular function}

Microvascular function of the resistance arteries was impaired in COPD patients with $\mathrm{pO}_{2}$ $\leq 65 \mathrm{~mm} \mathrm{Hg}$, as FBF during reactive hyperemia 
A

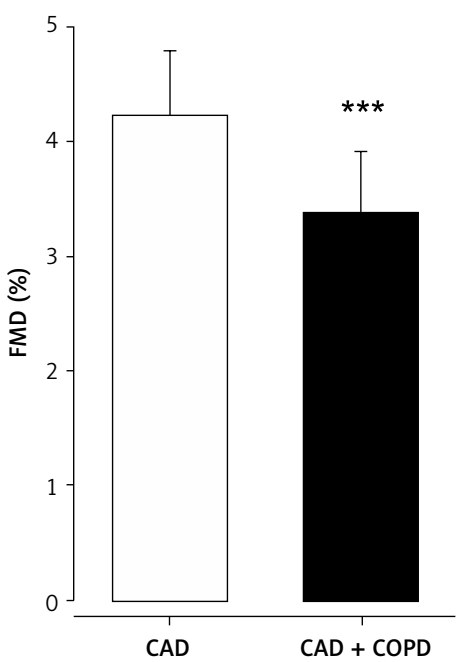

D

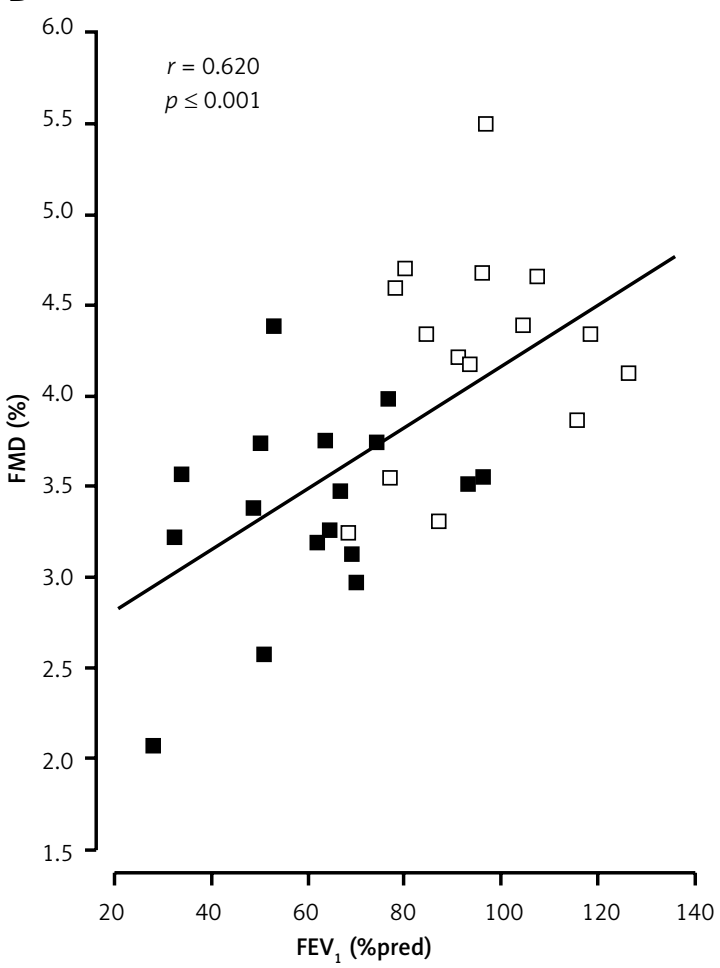

B

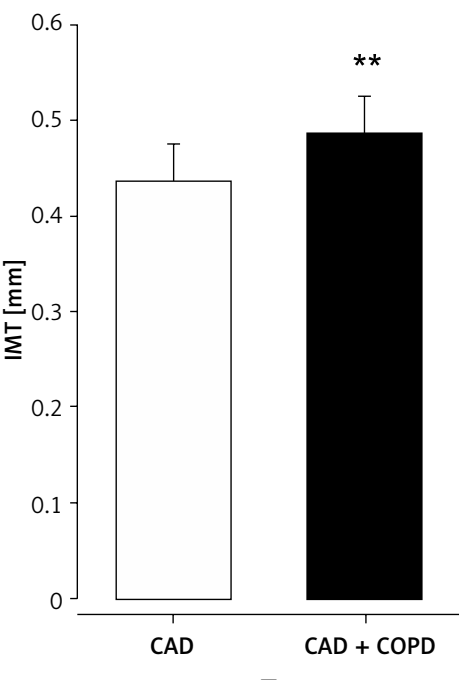

C

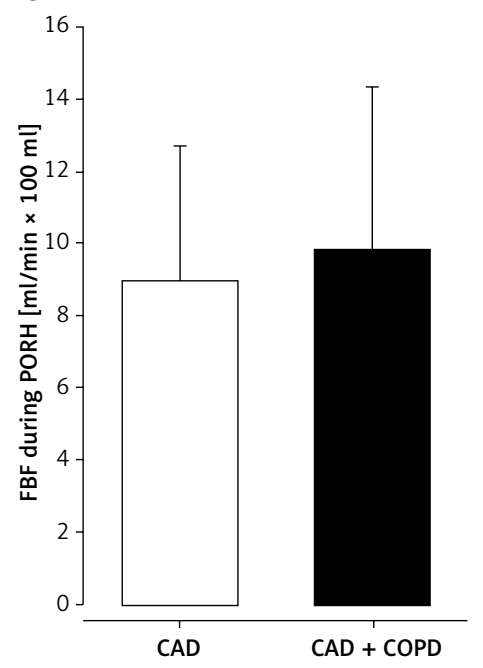

$\mathrm{E}$

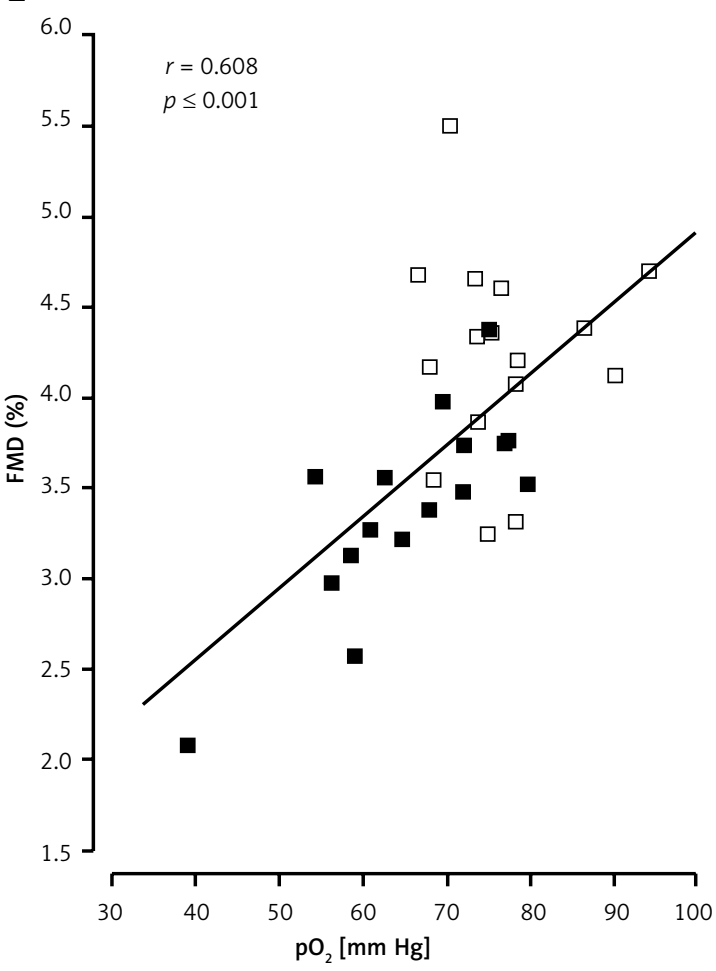

$\square$ CAD

$C A D+C O P D$

Figure 2. Vascular dysfunction in stable COPD and correlation of flow-mediated dilation (FMD) with FEV and $\mathrm{pO}_{2}$. Flow-mediated dilation (FMD; A) and intima-media thickness (IMT; B) of the brachial artery were significantly impaired in patients with coronary artery disease and coexisting COPD (CAD + COPD) in comparison to control patients with coronary artery disease (CAD), while forearm blood flow during postocclusive reactive hyperemia (FBF during PORH; C) was comparable between study groups. CAD + COPD is presented as black bars, CAD as open bars. ${ }^{* *} p \leq 0.01 ;{ }^{* \star *} p \leq 0.001$. FMD showed significant correlations with forced expiratory volume in $1 \mathrm{~s} \%$ predicted (FEV \% $\%$ pred; $r=0.620, p \leq 0.001 ; \mathrm{D})$ and with partial oxygen pressure $\left(\mathrm{pO}_{2} ; r=0.608, p \leq 0.001 ; \mathrm{E}\right)$ in the full study population. Patients with coronary artery disease and chronic obstructive pulmonary disease (CAD + COPD) are presented as black boxes, CAD as open boxes

was significantly reduced $(7.1 \pm 3.7$ vs. 11.9 $\pm 4.2 \mathrm{ml} / \mathrm{min} \times 100 \mathrm{ml}$ tissue, $p=0.030$; Figure $3 \mathrm{C}$ ), while FBF at rest showed comparable results between the subgroups $(1.4 \pm 1.1$ vs. 1.5 $\pm 1.0 \mathrm{ml} / \mathrm{min} \times 100 \mathrm{ml}$ tissue, $p=0.900)$. Micro- vascular function of the cutaneous capillaries was not different between the subgroups (baseline perfusion: $44 \pm 22$ vs. $39 \pm 11 \mathrm{PU} ; p=0.554$, maximum perfusion: $123 \pm 40$ vs. $131 \pm 36 \mathrm{PU}$; $p=0.675)$. 
Table II. Correlations between vascular function and structure with $\mathrm{FEV}_{1}$ and $\mathrm{pO}_{2}$

\begin{tabular}{|lcccc|}
\hline Parameter & \multicolumn{2}{c}{$\mathrm{FEV}_{1}$} & \multicolumn{2}{c|}{$\mathrm{pO}_{2}$} \\
\cline { 2 - 5 } & $r$ & $p$ & -0.263 & $p$ \\
\hline Brachial artery diameter & 0.090 & 0.631 & 0.608 & 0.145 \\
\hline FMD & 0.588 & $<0.001$ & -0.453 & 0.001 \\
\hline IMT & -0.455 & 0.013 & -0.132 & 0.479 \\
\hline FBF at rest & 0.079 & 0.679 & 0.203 & 0.273 \\
\hline FBF during reactive hyperemia & 0.159 & 0.403 & -0.497 & 0.003 \\
\hline Baseline skin perfusion & -0.455 & 0.009 & -0.111 & 0.539 \\
\hline Maximum skin perfusion & -0.236 & 0.193 & & \\
\hline
\end{tabular}

FMD - flow-mediated dilation, IMT-intima-media thickness, FBF-forearm blood flow, PORH-postocclusive reactive hyperemia, $r$-linear regression coefficient.

A

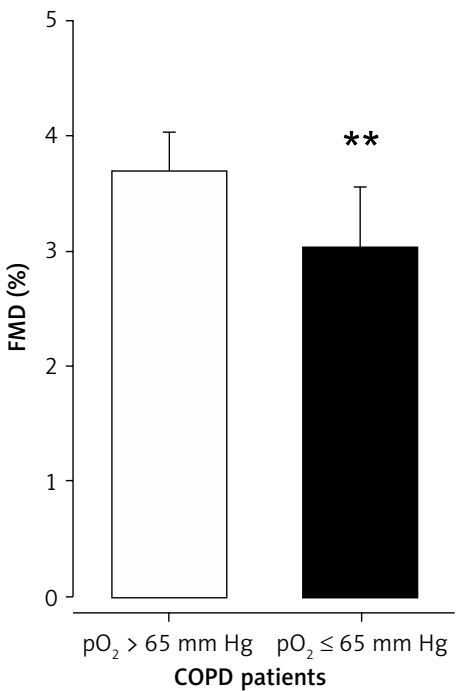

B

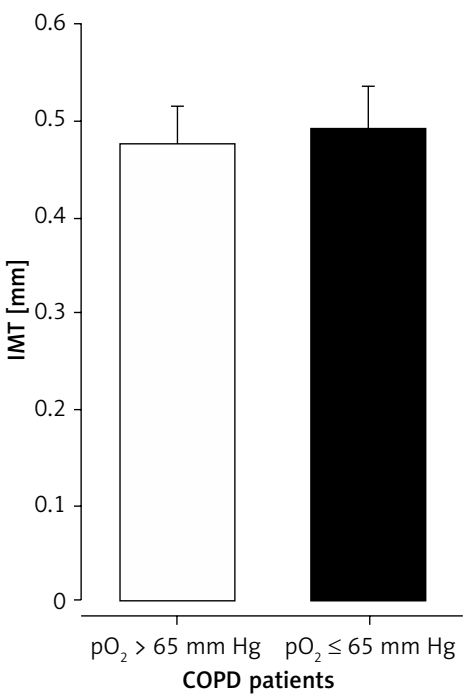

C

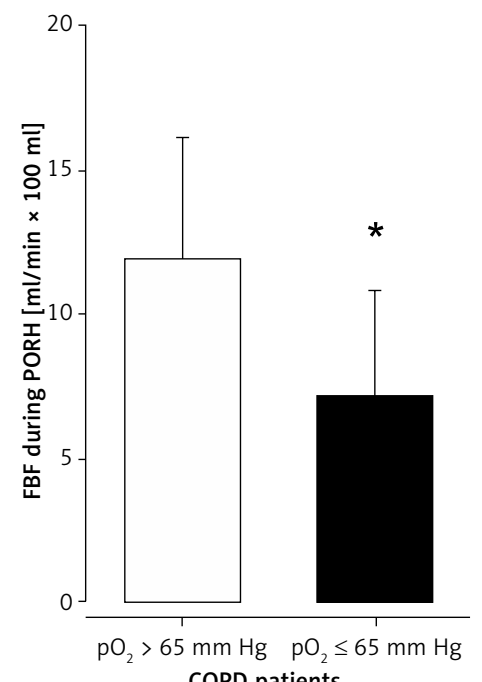

COPD patients

Figure 3. Endothelial dysfunction in stable COPD with reduced oxygen pressure. Flow-mediated dilation (FMD; A) of the brachial artery and forearm blood flow during postocclusive reactive hyperemia (FBF during PORH; C) were significantly impaired in patients with COPD and reduced oxygen pressure $\left(\mathrm{pO}_{2} ; \mathrm{COPD} \leq 65 \mathrm{~mm} \mathrm{Hg}\right)$ in comparison to patients with COPD with $\mathrm{pO}_{2}>65 \mathrm{~mm} \mathrm{Hg}$ (COPD > $65 \mathrm{~mm} \mathrm{Hg}$ ) in the subgroup analysis of COPD patients. Intima-media thickness (IMT; B) of the brachial artery was comparable between the subgroups. COPD $\leq 65 \mathrm{~mm} \mathrm{Hg}$ is presented as dark grey bars, COPD $>65 \mathrm{~mm} \mathrm{Hg}$ as light grey bars. ${ }^{*} p \leq 0.05$; ${ }^{* *} p \leq 0.01$

Experimental study to evaluate the significance of the oxygen level for vascular function in healthy volunteers

To evaluate the significance of the oxygen level for vascular function, an interventional study was performed comparing the vascular function while breathing $100 \%$ oxygen (hyperoxemia) or $12 \%$ oxygen (hypoxemia) in comparison to room air in a double blind study design.

\section{Comparison of hyperoxemia with room air}

Breathing $100 \%$ oxygen increased capillary $\mathrm{pO}_{2}$ from $87 \pm 9 \mathrm{~mm} \mathrm{Hg}$ to $273 \pm 36 \mathrm{~mm} \mathrm{Hg}(p \leq 0.001)$, while $\mathrm{pCO}_{2}$ remained unchanged $(41 \pm 2 \mathrm{~mm} \mathrm{Hg}$ vs. $39 \pm 4 \mathrm{~mm} \mathrm{Hg}, p=0.297)$. Brachial artery di- ameter (3.94 \pm 0.37 vs. $3.93 \pm 0.38 \mathrm{~mm}, p=0.969$ ) and FMD (7.08 $\pm 0.29 \%$ vs. $6.91 \pm 0.52 \%, p=0.666$; Figure 4) remained unchanged. Also, microvascular function was not affected. The FBF at rest (1.24 \pm 0.50 vs. $1.38 \pm 0.42, p=0.342)$ and FBF during reactive hyperemia (13.25 \pm 5.61 vs. $10.47 \pm 2.42$, $p=0.312$ ) as well as baseline perfusion by LDPI (30 \pm 5 vs. $35 \pm 6 \mathrm{PU}, p=0.180$ ) and maximum perfusion during reactive hyperemia (235 \pm 27 vs. $237 \pm 40 \mathrm{PU}, p=0.842$ ) remained unchanged.

\section{Comparison of hypoxemia with room air}

Breathing $12 \%$ oxygen reduced capillary $\mathrm{pO}_{2}$ from $87 \pm 9 \mathrm{~mm} \mathrm{Hg}$ to $70 \pm 7 \mathrm{~mm} \mathrm{Hg}(p=0.008)$. $\mathrm{CO}_{2}$ pressure was slightly, but significantly, reduced (41 $\pm 2 \mathrm{~mm} \mathrm{Hg}$ vs. $39 \pm 2 \mathrm{~mm} \mathrm{Hg} ;=0.035$ ), which 
A

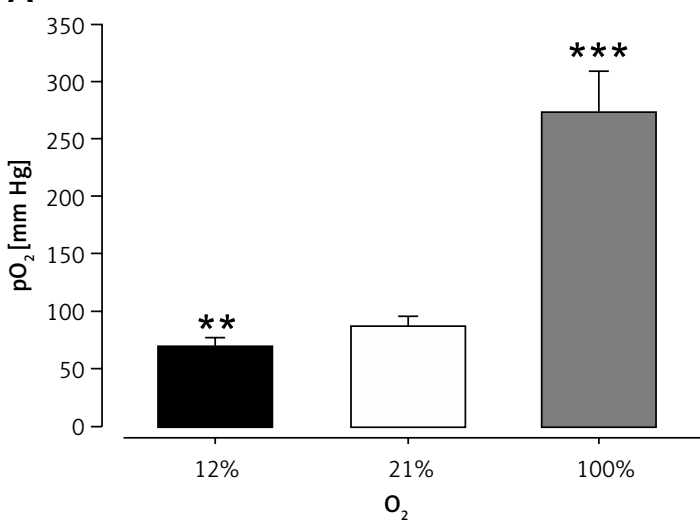

C

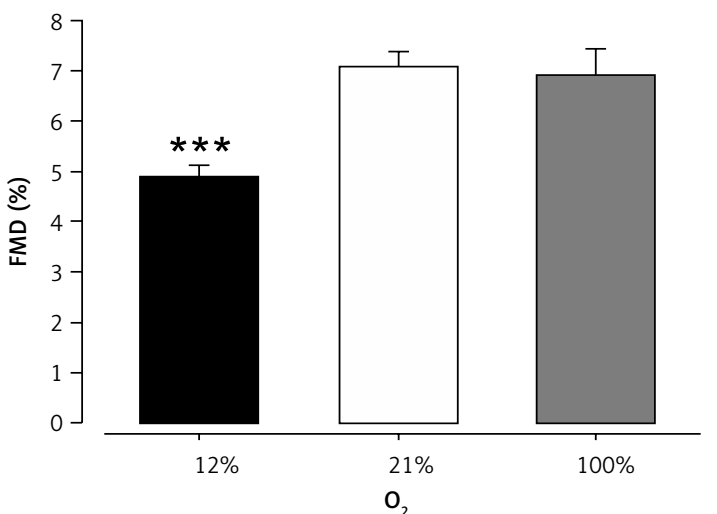

B

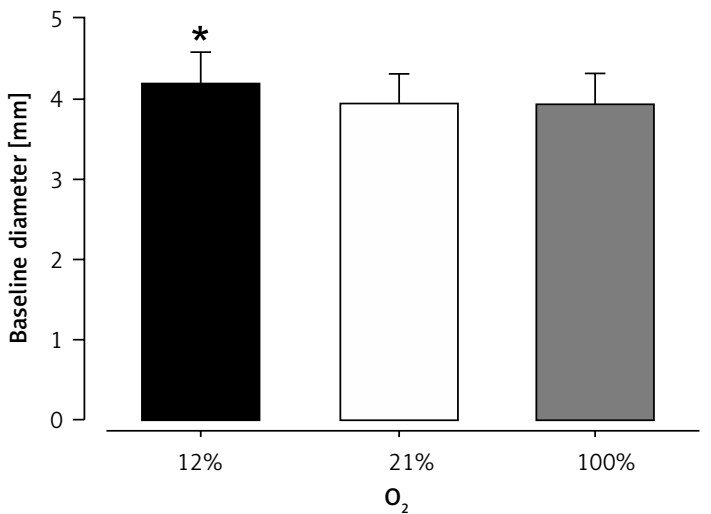

D

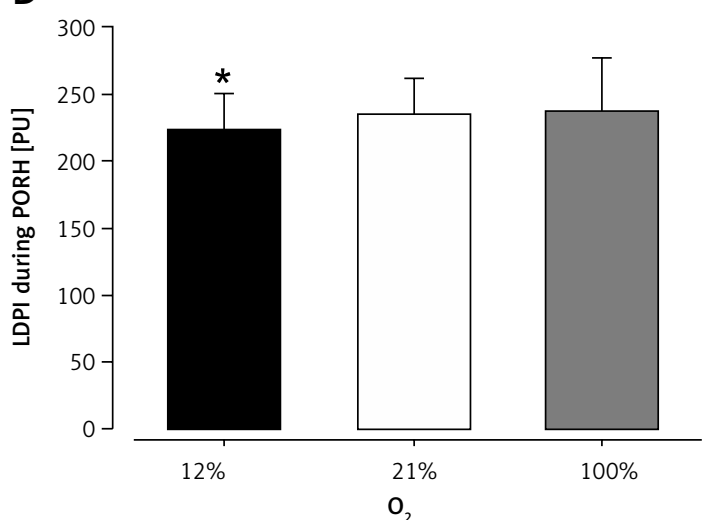

Figure 4. Endothelial dysfunction in response to acute hypoxemia in healthy subjects. Inhalation of oxygen $\left(\mathrm{O}_{2}\right)$ poor air $\left(12 \% \mathrm{O}_{2}\right)$ induced lowered capillary $\mathrm{pO}_{2}$ levels, while inhalation of $\mathrm{O}_{2}$ rich air $\left(100 \% \mathrm{O}_{2}\right)$ induced increased capillary $\mathrm{pO}_{2}$ levels in comparison to room air $\left(21 \% \mathrm{O}_{2}\right)(A)$ in healthy subjects. Inhalation of $\mathrm{O}_{2}$ poor air led to vasodilation of the brachial artery $(B)$, reduced flow-mediated dilation (FMD; $C$ ) and reduced maximum perfusion of the cutaneous microcirculation during postocclusive reactive hyperemia (PORH) by laser Doppler perfusion imaging (LDPI; D) in comparison to room air $\left(21 \% \mathrm{O}_{2}\right)$. Inhalation of oxygen rich air $\left(100 \% \mathrm{O}_{2}\right)$ did not change brachial artery diameter (B), FMD (C) or maximum perfusion during PORH (D). Inhalation of oxygen poor air is presented as black bars, inhalation of room air is presented as open bars, and inhalation of oxygen rich air is presented as grey bars. ${ }^{*} p \leq 0.05 ;{ }^{* *} p \leq 0.01 ;{ }^{* * *} p \leq 0.001$ each versus room air

indicates hypoxemic hyperventilation. Hypoxemia led to an increased diameter of the brachial artery (3.94 \pm 0.37 vs. $4.18 \pm 0.38 \mathrm{~mm}, p=0.014$ ), suggesting hypoxemic vasodilation. The FMD was significantly impaired in response to hypoxemia (7.08 $\pm 0.29 \%$ vs. $4.89 \pm 0.24 \%$; $p \leq 0.001$, Figure 4 ). Hypoxemia was also associated with microvascular dysfunction, as detected by the impaired response of the cutaneous capillary bed to reactive hyperemia (baseline perfusion: $30 \pm 5$ vs. $36 \pm 6, p=0.133$, maximum perfusion during reactive hyperemia: $235 \pm 27$ vs. $223 \pm 28, p=0.048$ ). Resistance arteries showed a reduced response, but the difference was not statistically significant (FBF at rest: $1.24 \pm 0.51$ vs. 1.69 $\pm 0.96 \mathrm{ml} / \mathrm{min} \times 100 \mathrm{ml}$ tissue, $p=0.161$; FBF during reactive hyperemia: $13.25 \pm 5.61$ vs. $7.61 \pm 1.34 \mathrm{ml}$ $\min \times 100 \mathrm{ml}$ tissue; $p=0.096$ ).

\section{Discussion}

The main result of the study was that COPD was associated with lower flow-mediated vaso- dilation, a clinical marker of endothelial function, in patients with coronary artery disease. Furthermore, oxygen tension was an independent predictor of flow-mediated vasodilation in patients, and we present experimental data showing that low oxygen tension acutely lowered flow-mediated vasodilation.

Herein, we showed for the first time in patients with proven atherosclerotic disease that coexisting COPD is associated with more pronounced systemic vascular dysfunction as detected by impaired FMD, a marker of endothelial function, and increased IMT, a marker of atherosclerotic vascular remodeling. Of note, no patient was a current smoker, excluding effects of acute smoking or acute deprivation from smoking on vascular function. Previously, impaired FMD has been shown in stable COPD patients without proven atherosclerotic disease [14] or in heterogeneous groups with and without atherosclerotic disease $[13,15,27$, 28]. The authors argued that endothelial dysfunc- 
tion in these patients might explain the increased risk of cardiovascular disease in COPD patients. Our results extend these findings by further underscoring the relevance of COPD in vascular biology by showing that effects of COPD are also present during late stages of atherogenesis, namely in the presence of relevant atherosclerotic disease. Corresponding with epidemiological data, we and others have shown a relation between $\mathrm{FEV}_{1}$ and FMD [13-15] or IMT [19, 20, 29], underlining the concept of an interaction between the pulmonary and cardiovascular system.

Microvascular function in COPD patients is poorly described in the literature. In our present study, we did not detect differences in vascular function of resistance arteries and cutaneous capillaries of the upper extremity between CAD patients with or without coexisting COPD. When comparing COPD patients with healthy smoking control subjects, others have found no difference in forearm blood flow during intrabrachial infusions of bradykinin, acetylcholine, sodium nitroprusside, and verapamil [30]. Also, no differences in baseline and hyperemic blood flow in the brachial artery during reactive hyperemia were observed [14]. This suggests that COPD may not significantly further aggravate microvascular dysfunction in CAD patients. As microvascular function is one of the major determinants of conduit artery FMD, these results further strengthen our findings pointing to a negative effect of COPD on the macro-circulation, as described above.

Our experimental results suggest that macro-vascular endothelial dysfunction in COPD patients may be related to hypoxia. In previous studies investigating vascular function in COPD, no correlation of FMD and $\mathrm{pO}_{2}$ has been investigated $[13,14,27,28]$ or found $[15,31]$.

Endothelial function as a key aspect of the disturbed vascular biology throughout the natural history of atherosclerosis is widely assessed as FMD, which is primarily mediated by endothelial NOS activation through shear stress [32]. As oxygen is an important cofactor of eNOS, it is conceivable that low oxygen may curb NOS activity and decrease FMD. However, this has not been studied in humans in vivo. Others have shown that acute hypoxemia induces vasodilation of the brachial artery and resistance arteries [33, 34]. Above, we showed that hypoxemia leads to substantial functional impairment during the postischemic response as detected by reduced FMD and FBF in healthy subjects. The role of chronic hypoxemia for vascular function in chronic pulmonary disease has been poorly investigated until now. Herein, we present a significant correlation of FMD and $\mathrm{pO}_{2}$ that is independent of $\mathrm{FEV}_{1}$ and pack years of smoking. Correspondingly, the subgroup analysis in COPD pa- tients showed impaired FMD in COPD patients with lower $\mathrm{pO}_{2}$. Our present data are in line with the hypothesis that low oxygen contributes to endothelial dysfunction, which may help explain accelerated atherogenesis in COPD patients, and that this may be due to impaired nitric oxide bioavailability.

One limitation of the study is the heterogeneity of the antiobstructive or anti-inflammatory medication in COPD patients. Patients were treated with anticholinergics, with a $\beta 2$-agonist or inhaled steroids, with a combination of the aforementioned medication, or were untreated. The small number of study subjects did not allow an adequate analysis of the effect of antiobstructive and anti-inflammatory medication on vascular function. In future studies, the effect of antiobstructive or anti-inflammatory medication in COPD patients should be addressed. At this point it remains unclear whether the observed effects ascribed to hypoxia are influenced by antiobstructive treatment and whether the treatment may even have negative effects on vascular function.

When evaluating the effect of hypoxemia on endothelial function, the interaction between vasodilation or baseline artery diameter has to be carefully considered. In COPD patients, previous studies also found peripheral vasodilation in comparison to control subjects $[14,28]$. However, subgroup analysis in COPD patients did not reveal increasing brachial artery diameters in dependence of COPD severity [14]. We did not find differences in baseline diameter when comparing patients with or without coexisting COPD and when comparing patient with $\mathrm{pO}_{2}>65 \mathrm{~mm} \mathrm{Hg}$ or $\mathrm{pO}_{2} \leq 65 \mathrm{~mm} \mathrm{Hg}$ in subgroup analysis in COPD patients, and no correlation was found between baseline diameters and $\mathrm{pO}_{2}$ in the patient cohort. Besides a potential direct influence of hypoxemia, alterations in autonomic nervous system determine vessel tone, and size may play a role that was not investigated in the present study. Furthermore, increased peripheral artery diameter as a part of the hydraulic overload has been discussed in this context [28].

In conclusion, we demonstrated aggravated endothelial dysfunction in patients with CAD and coexisting COPD as compared with sole CAD. Our data suggest that in CAD patients with COPD, decreased systemic oxygen levels contribute to vascular dysfunction and that acutely decreasing oxygen levels in healthy subjects induces endothelial dysfunction. These results underline the relevance of cardiopulmonary interaction and the potential importance of pulmonary treatment in primary and secondary prevention of vascular disease.

\section{Acknowledgments}

Two of the authors are funded by the Deutsche Forschungsgemeinschaft. 


\section{Conflict of interest}

The authors declare no conflict of interest.

\section{References}

1. Sidney S, Sorel M, Quesenberry CP, et al. COPD and incident cardiovascular disease hospitalizations and mortality: Kaiser Permanente Medical Care Program. Chest 2005; 128: 2068-75.

2. Anthonisen NR, Connett JE, Enright PL, et al. Hospitalizations and mortality in the Lung Health Study. Am J Respir Crit Care Med 2002; 166: 333-9.

3. Straburzynska-Migaj E, Kaluzna-Oleksy M, Maggioni AP, et al. Patients with heart failure and concomitant chronic obstructive pulmonary disease participating in the Heart Failure Pilot Survey (ESC-HF Pilot) - Polish population. Arch Med Sci 2015; 11: 743-50.

4. Salisbury AC, Reid KJ, Spertus JA. Impact of chronic obstructive pulmonary disease on post-myocardial infarction outcomes. Am J Cardiol 2007; 99: 636-41.

5. Gardner SC, Grunwald GK, Rumsfeld JS, et al. Risk factors for intermediate-term survival after coronary artery bypass grafting. Ann Thorac Surg 2001; 72: 2033-7.

6. Berger JS, Sanborn TA, Sherman W, et al. Effect of chronic obstructive pulmonary disease on survival of patients with coronary heart disease having percutaneous coronary intervention. Am J Cardiol 2004; 94: 649-51.

7. Sin DD, Wu L, Man SF. The relationship between reduced lung function and cardiovascular mortality: a population-based study and a systematic review of the literature. Chest 2005; 127: 1952-9.

8. Macnee W, Maclay J, McAllister D. Cardiovascular injury and repair in chronic obstructive pulmonary disease. Proc Am Thorac Soc 2008; 5: 824-33.

9. Wozniak K, Sleszycka J, Safianowska A, Wiechno W, Domagala-Kulawik J. Systemic inflammation in peripheral arterial disease with or without coexistent chronic obstructive pulmonary disease: analysis of selected markers. Arch Med Sci 2012; 8: 477-83.

10. Antczak A, Ciebiada M, Pietras T, Piotrowski WJ, Kurmanowska Z, Gorski P. Exhaled eicosanoids and biomarkers of oxidative stress in exacerbation of chronic obstructive pulmonary disease. Arch Med Sci 2012; 8 277-85.

11. Neukamm A, Hoiseth AD, Einvik G, et al. Rosuvastatin treatment in stable chronic obstructive pulmonary disease (RODEO): a randomized controlled trial. J Intern Med 2015; 278: 59-67.

12. Pizarro S, Garcia-Lucio J, Peinado VI, et al. Circulating progenitor cells and vascular dysfunction in chronic obstruc tive pulmonary disease. PLoS One 2014; 9: e106163.

13. Barr RG, Mesia-Vela S, Austin JH, et al. Impaired flow-mediated dilation is associated with low pulmonary function and emphysema in ex-smokers: the Emphysema and Cancer Action Project (EMCAP) Study. Am J Respir Crit Care Med 2007; 176: 1200-7.

14. Eickhoff P, Valipour A, Kiss D, et al. Determinants of systemic vascular function in patients with stable chronic obstructive pulmonary disease. Am J Respir Crit Care Med 2008; 178: 1211-8.

15. Clarenbach CF, Senn O, Sievi NA, et al. Determinants of endothelial function in patients with COPD. Eur Respir J 2013; 42: 1194-204.

16. Sabit R, Bolton CE, Edwards $\mathrm{PH}$, et al. Arterial stiffness and osteoporosis in chronic obstructive pulmonary dis ease. Am J Respir Crit Care Med 2007; 175: 1259-65.
17. McAllister DA, Maclay JD, Mills NL, et al. Arterial stiffness is independently associated with emphysema severity in patients with chronic obstructive pulmonary disease. Am J Respir Crit Care Med 2007; 176: 1208-14.

18. van Gestel YR, Flu WJ, van Kuijk JP, et al. Association of COPD with carotid wall intima-media thickness in vascular surgery patients. Respir Med 2010; 104: 712-6.

19. Barr RG, Ahmed FS, Carr JJ, et al. Subclinical atherosclerosis, airflow obstruction and emphysema: the MESA Lung Study. Eur Respir J 2012; 39: 846-54.

20. Schroeder EB, Welch VL, Evans GW, et al. Impaired lung function and subclinical atherosclerosis. The ARIC Study. Atherosclerosis 2005; 180: 367-73.

21. Global Strategy for the Diagnosis, Management and Prevention of COPD, Global Initiative for Chronic Obstructive Lung Disease (GOLD) 2013. Available from: http://www.goldcopd org.

22. Heiss C, Keymel S, Niesler U, et al. Impaired progenitor cell activity in age-related endothelial dysfunction. J Am Coll Cardiol 2005; 45: 1441-8.

23. Balzer J, Boos M, Rassaf T, et al. "One Stop-Shop” ultrasound diagnosis of functional, structural and physicomechanical properties of the brachial artery. Vasa 2007; 36: $100-6$

24. Wendelhag I, Liang Q, Gustavsson W, et al. A new automated computerized analyzing system simplifies readings and reduces the variability in ultrasound measurement of intima-media thickness. Stroke 1997; 28: 2195-200.

25. Lauer T, Heiß C, Preik M, et al. Reduction of peripheral flow reserve impairs endothelial function in conduit arteries of patients with essential hypertension. J Hypertens 2004; 23: 563-9.

26. Keymel S, Sichwardt J, Balzer J, et al. Characterization of the non-invasive assessment of the cutaneous microcirculation by laser Doppler perfusion scanner. Microcirculation 2010; 17: 358-66

27. Moro L, Pedone C, Scarlata S, et al. Endothelial dysfunction in chronic obstructive pulmonary disease. Angiology 2008; 59: 357-64.

28. Blum A, Simsolo C, Sirchan R. Vascular responsiveness in patients with chronic obstructive pulmonary disease (COPD). Eur J Intern Med 2014; 25: 370-3.

29. Iwamoto H, Yokoyama A, Kitahara Y, et al. Airflow limitation in smokers is associated with subclinical atherosclerosis. Am J Respir Crit Care Med 2009; 179: 35-40.

30. Maclay JD, McAllister DA, Mills NL, et al. Vascular dysfunction in chronic obstructive pulmonary disease. Am J Respir Crit Care Med 2009; 180: 513-20.

31. Boyer L, Chaar V, Pelle G, et al. Effects of polycythemia on systemic endothelial function in chronic hypoxic lung disease. J Appl Physiol 2011; 110: 1196-203.

32. Charakida M, Masi S, Luscher TF, et al. Assessment of atherosclerosis: the role of flow-mediated dilatation. Eur Heart J 2010; 31: 2854-61.

33. Blitzer ML, Loh E, Roddy MA, et al. Endothelium-derived nitric oxide regulates systemic and pulmonary vascular resistance during acute hypoxia in humans. J Am Coll Cardiol 1996; 28: 591-6.

34. Spilk S, Herr MD, Sinoway LI, et al. Endothelium-derived hyperpolarizing factor contributes to hypoxia-induced skeletal muscle vasodilation in humans. Am J Physiol Heart Circ Physiol 2013; 305: H1639-45. 